\title{
Neurological Complications of Cardiac Procedures
}

\author{
Courtney M. Hrdlicka, MD ${ }^{1, *}$ Jeffrey Wang, MD ${ }^{2, *}$ Magdy Selim, MD, PhD ${ }^{3}$ \\ ${ }^{1}$ Mayo Clinic Arizona, Scottsdale, Arizona \\ ${ }^{2}$ Division of Neurology, Department of Medicine, University of \\ Toronto, St. Michael's Hospital, Toronto, Ontario, Canada

\begin{abstract}
Address for correspondence Jeffrey Wang, MD, University of Toronto, St. Michael's Hospital, 30 Bond Street, Toronto, ON, Canada M5B1W8 (e-mail: jeff.wang@unityhealth.to).
\end{abstract}

3 Department of Neurology, Harvard Medical School, Beth Israel

Deaconess Medical Center, Boston, Massachusetts

Semin Neurol 2021;41:398-410.

\author{
Abstract \\ Keywords \\ - stroke \\ - coronary artery \\ bypass graft \\ - percutaneous \\ coronary intervention \\ - transcatheter aortic \\ valve implantation \\ - perioperative \\ complication
}

Neurological complications after cardiac surgery and percutaneous cardiac interventions are not uncommon. These include periprocedural stroke, postoperative cognitive dysfunction after cardiac surgery, contrast-induced encephalopathy after percutaneous interventions, and seizures. In this article, we review the incidence, pathophysiology, diagnosis, and management of these complications. Improved understanding of these complications could lead to their prevention, faster detection, and facilitation of diagnostic workup and appropriate treatment.

As surgical and interventional cardiac procedures advance in both volume and complexity, clinicians will encounter an increasing number of patients who present with neurological symptoms related to a cardiac procedure. In this article, we will review the major central nervous system complications of cardiac procedures including open surgeries as well as percutaneous procedures such as percutaneous coronary intervention (PCI) and transcatheter aortic valve implantation (TAVI). As the target reader consists mainly of clinical neurologists, our focus will be on diagnosis, treatment, and secondary prevention, with a cursory discussion of primary prevention strategies.

\section{Stroke}

Stroke is by far the most clinically important and well-studied perioperative neurological complication after cardiac procedures. In general, stroke is considered to be perioperative if occurring within 30 days from the procedure. ${ }^{1,2}$

\footnotetext{
* Authors contributed equally to the manuscript.
}

published online June 16, 2021
Issue Theme Neurology of Cardiovascular Disease; Guest Editors: Sung-Min Cho, DO, MHS, and Romergryko G. Geocadin, MD, FNCS, FAAN, FANA

\section{Incidence}

The reported incidence of perioperative stroke varies according to the type of procedure ( - Table 1 ). Stroke occurs in 1.1 to $4.1 \%$ of patients undergoing coronary artery bypass graft (CABG) and 0.1 to $0.5 \%$ of those undergoing PCI. ${ }^{1-5}$ While many large prospective and observational studies have demonstrated that periprocedural stroke rates are lower following PCI compared with $C A B G,{ }^{1,2}$ the literature is less robust for complication rates from valvular repair and replacement procedures. Registry studies of both CABG and PCI from the 2000s have reported lower incidences of periprocedural stroke compared with similar studies from the two preceding decades. ${ }^{2,5,6}$ However, some prospective and retrospective studies have shown either stable or even increasing rates of periprocedural stroke from the mid-1990s to the 2000s, with authors hypothesizing that advances in procedural technique are offset by the increasing proportion of high-risk patients being considered eligible for surgery. ${ }^{1,4}$ In interpreting incidence data for perioperative stroke, one must keep in mind the high degree of heterogeneity in study type, the authors' definition of stroke, and the method of ascertainment of stroke occurrence.

(c) 2021. Thieme. All rights reserved. Thieme Medical Publishers, Inc., 333 Seventh Avenue, 18th Floor, New York, NY 10001, USA
DOI https://doi.org/ 10.1055/s-0041-1728761. ISSN 0271-8235. 
Table 1 Incidence of stroke at 30 days by type of procedure

\begin{tabular}{|l|l|l|}
\hline $\begin{array}{l}\text { Procedure } \\
\text { type }\end{array}$ & Procedure & $\begin{array}{l}\text { Incidence of } \\
\text { periprocedural } \\
\text { stroke (\%) }\end{array}$ \\
\hline Surgical & Isolated CABG & $1.1-4.1^{1-4}$ \\
\cline { 2 - 3 } & $\begin{array}{l}\text { Combined CABG } \\
\text { and valve }\end{array}$ & $7.4-7.9^{3,4}$ \\
\cline { 2 - 3 } & Isolated AVR & $1.5-4.8^{12,109,110}$ \\
\cline { 2 - 3 } & Isolated MVR & $1.4-8.8^{3,110}$ \\
\cline { 2 - 3 } & $\begin{array}{l}\text { Multiple valve } \\
\text { surgery }\end{array}$ & $9.7^{3}$ \\
\cline { 2 - 3 } & Aortic repair & $4.7-7.2^{111,112}$ \\
\hline Percutaneous & PCI & $0.18-0.5^{1,2,5}$ \\
\cline { 2 - 3 } & TAVI & $2.7^{12}$ \\
\hline
\end{tabular}

Abbreviations: AVR, aortic valve replacement; $C A B G$, coronary artery bypass graft; MVR, mitral valve repair; $\mathrm{PCl}$, percutaneous coronary intervention; TAVI, transcatheter aortic valve implantation.

Technical aspects of the individual procedures may account for some of the differences in perioperative stroke risk. Among the myriad techniques in cardiac procedures, one of the most extensively studied is off-pump CABG (OPCABG), in which coronary anastomosis is achieved without the use of cardiopulmonary bypass. One meta-analysis of 40 randomized trials found a pooled in-hospital stroke incidence of $1.34 \%$ in the OPCABG group compared with $2.00 \%$ in the CABG group (odds ratio $[\mathrm{OR}], 0.72 ; 95 \%$ confidence interval $[\mathrm{CI}], 0.56-0.92$; $\left.p=0.009 ; I^{2}=0 \%\right)^{7}$ However, none of the three largest randomized controlled trials evaluating OPCABG, each with over 2,000 subjects, found a significant reduction in the rate of in-hospital stroke. It remains controversial whether this technique in fact decreases the risk of perioperative stroke compared with conventional CABG. ${ }^{8}$

Cardiac catheterization also carries a different risk of stroke depending on whether or not an intervention is performed. For example, one large single-center retrospective study examining the rate of periprocedural stroke found an incidence of $0.09 \%$ for purely diagnostic cardiac catheterizations, versus $0.23 \%$ for which an intervention such as $\mathrm{PCI}$ is performed. ${ }^{9}$

Another procedure that deserves further discussion is TAVI, now well accepted as a less invasive alternative to surgical aortic valve replacement (AVR). Two early landmark trials using the same first-generation device found a 30-day incidence of stroke of $6.7 \%$ in patients who were not surgical candidates, and $4.6 \%$ in high-risk patients who were otherwise surgical candidates (compared with $2.4 \%$ in the surgical arm, $p=0.07) .{ }^{10,11}$ However, subsequent trials reported substantially lower 30-day incidences of stroke, possibly attributable to improvements in device and technique, inclusion of lower risk individuals, as well as more rigorous adjudication methodology. A recent meta-analysis of 22 propensity score-matched observational studies and 6 randomized controlled trials found a 30-day rate of stroke of 2.7 and $3.1 \%$ in the TAVI and surgical AVR groups, respectively, without statistically significant difference. ${ }^{12}$ In recent years, cerebral embolic protection devices have emerged as a promising means to decrease the burden of both clinical and subclinical embolic infarcts resulting from TAVI. However, the clinical efficacy of these devices remains to be proven in large randomized controlled studies. ${ }^{13}$

Lastly, it is important to note that the aforementioned incidence data are largely based on a clinical definition of stroke, consisting of a focal neurological deficit persisting for more than 24 hours, with or without adjudication by a neurologist. The periprocedural rate of clinically "silent" infarcts detectable on MRI is in fact many times higher than symptomatic strokes. A 2017 meta-analysis of studies in which early postprocedural MRI was performed found a staggering rate of radiographic infarcts in $27 \%$ of patients undergoing CABG and $80 \%$ of those undergoing TAVI. In the same study, the rate of radiographic infarcts was 10 times that of the combined rate of clinical strokes and transient ischemic attacks (TIAs). ${ }^{14}$ The cognitive consequences of silent brain infarcts will be discussed later in this article.

\section{Timing and Mechanism}

In patients who undergo CABG, less than half of perioperative strokes are identified upon awakening from anesthesia, that is, presumed to have occurred intraoperatively, whereas the remaining 55 to $63 \%$ of patients are diagnosed from the first postoperative day onward. Most strokes are apparent within the first week. ${ }^{6,15,16}$ A similar temporal pattern of onset has been observed with TAVI, ${ }^{17}$ while corresponding data for PCI are lacking and conflicting. 9, 18

The large majority of strokes after cardiac procedures are ischemic as opposed to hemorrhagic. Proximal embolization from the heart or aortic arch is the most common etiology in both the intraoperative and postoperative periods. By contrast, hypoperfusion is a less common cause of stroke than most readers might expect. In a retrospective study examining etiology of 388 cases of stroke related to isolated CABG, $62.1 \%$ were determined to be embolic, and only $8.8 \%$ were deemed to be due to hypoperfusion. ${ }^{15}$ In the intraoperative period, embolism occurs due to release of particulate matter from manipulation of the aortic arch and heart as well as from the cardiopulmonary bypass pump. In the postoperative period, embolism occurs in the setting of increased thrombosis, including postoperative atrial fibrillation (POAF) and a general hypercoagulable state. ${ }^{15,19}$ Surgical trauma, general anesthesia, immobility, and perioperative holding of baseline antithrombotic medications all contribute to thromboembolism. Aortic plaques that were disturbed during the procedure may also cause delayed thromboembolism. However, not all periprocedural emboli are thrombotic in nature. In one study examining debris captured by an embolic protection device during TAVI, both thrombotic (73\%) and tissue-derived (63\%) debris were found with high prevalence. ${ }^{20}$ Uncommonly, a calcified embolus may be detected on noncontrast CT brain (-Fig. 1). ${ }^{21}$

In addition to cerebral infarction, this embolization of atherosclerotic plaque material can cause multisystem organ dysfunction, termed "cholesterol embolization syndrome." This can occur after either endovascular or open cardiac procedures, 


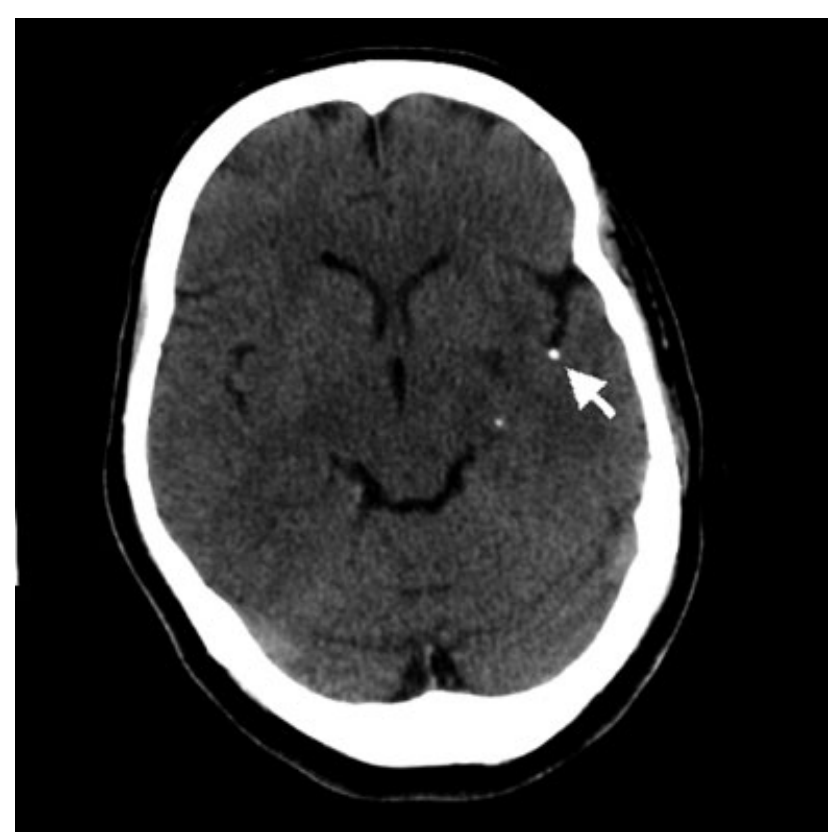

Fig. 1 A 59-year-old woman presented with aphasia 6 hours following a transcatheter aortic valve implantation procedure. Noncontrast CT head revealed a focal hyperdensity in the left Sylvian fissure consistent with a calcified embolus (arrow).

and is composed of organ-specific dysfunction and constitutional symptoms. Cerebral cholesterol embolization, particularly of a smaller shower of emboli, can lead to global neurologic dysfunction characterized by confusion or memory impairment rather than focal neurologic deficits. ${ }^{22}$ Unlike thromboemboli, cholesterol emboli can lead to progressive or new dysfunction postprocedurally; the inflammatory reaction surrounding nonocclusive cholesterol emboli can lead to intraluminal thrombus formation over the 24 to 48 hours following embolization. Infarction can also occur in an even more delayed fashion, as the late stages of the local inflammatory response lead to endothelial proliferation and intimal fibrosis, potentially causing delayed vascular stenosis or occlusion. ${ }^{22}$ Definitive diagnosis can only be made with biopsy of an affected tissue, but the concomitant presence of other organ-specific dysfunction can clue one in to the possibility that intracranial emboli may be cholesterol emboli. The most commonly affected organs are kidneys, skin, and the gastrointestinal tract. ${ }^{22,23}$ Careful examination may also reveal retinal Hollenhorst plaques. ${ }^{22,23}$ In the appropriate clinical setting, a pathologic diagnosis can be deferred and the diagnosis can be made clinically.

Although carotid artery stenosis has been consistently shown to be a risk factor for perioperative stroke, especially in the setting of CABG, there is controversy in the literature regarding its importance as a direct causal factor. ${ }^{24}$ One systematic review of small case series estimated that up to $67 \%$ of strokes after CABG cannot be attributed to carotid disease alone based on location (contralateral, bilateral, or posterior circulation involvement). ${ }^{25}$ Carotid artery stenosis can directly cause strokes via two potential mechanisms: hypoperfusion due to flow restriction and plaque rupture resulting in artery-to-artery embolism. Hypoperfusionrelated strokes can usually be distinguished from embolic strokes based on a temporal correlation with hypotension, the presence of an ipsilateral high-grade vascular stenosis, as well as a characteristic pattern of distribution on imaging (-Figs. 2 and 3). However, emboli may also preferentially travel to watershed zones.

Hemorrhagic strokes, which include primary intracerebral hemorrhage and subarachnoid hemorrhage, are very rare in the setting of cardiac procedures. ${ }^{9,15,26-28}$ Presumably these may be triggered by the use of high-dose antithrombotic medications in the periprocedural period in patients who are already at risk of spontaneous hemorrhagic stroke, such as those with cerebral small vessel disease, cerebral amyloid angiopathy, or unruptured aneurysms. Clinicians must be careful to avoid misdiagnosing an ischemic stroke with hemorrhagic transformation as a primary intracerebral hemorrhage. Other uncommon etiologies of stroke are listed in -Table 2.

\section{Risk Factors}

Risk factors for stroke following cardiac procedures are listed in - Table 3. Increased awareness of these risk factors can aid prevention strategies to minimize perioperative stroke risk. The most consistently reported risk factors for periprocedural stroke after cardiac procedures include female sex, previous stroke or TIA, atrial fibrillation (AF; preexisting and new onset), systolic dysfunction, and chronic renal disease. Because prior history of an ischemic cerebrovascular event is one of the strongest and most consistent predictors of periprocedural stroke, patients who have had a recent stroke or TIA should delay having any nonurgent cardiac procedures until their stroke workup and secondary prevention have been optimized.

The procedural approach also influences risk of stroke. For example, on-pump CABG is associated with a higher risk of perioperative stroke than OPCABG (beating heart CABG), though the latter is usually reserved for selected higher risk patients, due to higher technical difficulty. ${ }^{7,29-31}$ Predictive models for stroke risk following CABG based on readily available clinical variables have been proposed and validated. ${ }^{32,33}$

\section{Risk Factors: Carotid Stenosis}

The neurologist may be asked to assess patients with known high-grade (50-99\%) carotid stenosis in preparation for cardiac surgery. In these instances, it is vital to distinguish on history whether the carotid stenosis is symptomatic, which is generally defined as a history of TIA or stroke in the vascular territory of the stenotic carotid artery. Recent symptoms confer a much higher risk than remote symptoms, and many authors use a cut-off of 6 months as the window beyond which carotid artery stenosis is no longer considered "symptomatic," 34,35 though this is somewhat arbitrary. One of the few CABG outcome studies that distinguished between symptomatic and asymptomatic carotid disease found a perioperative stroke risk of 18 and $26 \%$ in unilateral and bilateral symptomatic disease, respectively. ${ }^{25}$

Asymptomatic high-grade carotid stenosis, while also a risk factor for perioperative stroke, may be considered an epiphenomenon for overall atherosclerotic burden rather than a significant mechanism of periprocedural stroke. There 


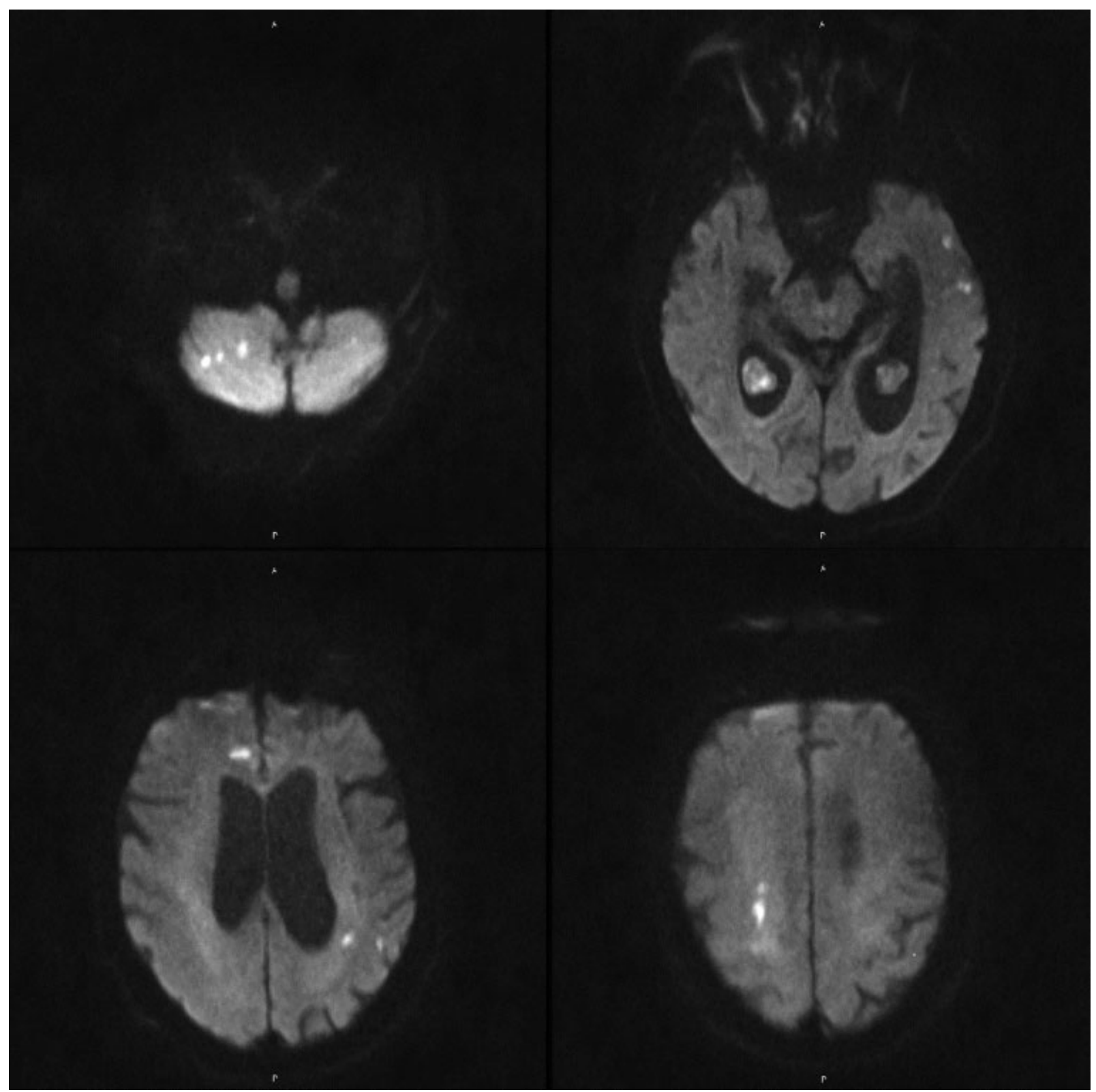

Fig. 2 An 82-year-old woman developed acute confusion 36 hours post-coronary artery bypass graft. Magnetic resonance imaging revealed punctate foci of diffusion restriction in multiple vascular territories consistent with proximal embolic "shower." Note that although clearly embolic, some of the infarcts occur in the deep watershed zone.

is no evidence to support routine prophylactic revascularization of unilateral asymptomatic carotid stenosis prior to CABG.

An additional category of carotid disease that must be considered separately is chronic carotid occlusion. While these patients have an even higher risk of perioperative stroke than those with 50 to $99 \%$ stenosis, ${ }^{25}$ revascularization is not advocated in chronic complete occlusion, and efforts should be directed toward other means to optimize surgical risk.

Accordingly, both American and European guidelines recommend that preoperative carotid revascularization be considered in only three instances: symptomatic high-grade stenosis, asymptomatic bilateral high-grade stenosis, or asymptomatic high-grade stenosis with contralateral carotid occlusion. ${ }^{35,36}$ Guidelines recommend against revasculariza- tion of asymptomatic unilateral carotid stenosis or stenosis $<50 \%$. Furthermore, as there is no evidence that routine preoperative screening for carotid stenosis reduces the risk of perioperative stroke, ${ }^{24}$ screening carotid duplex ultrasound should be limited to patients with a recent TIA or stroke, and those with high-risk features such as age $>65$ and known peripheral vascular disease. ${ }^{35,36}$

In patients with concurrent high-grade carotid disease and coronary artery disease requiring revascularization, $\mathrm{PCI}$ would generally be favored over CABG due to its lower risk of periprocedural stroke, though other factors may make CABG the only feasible option. Carotid revascularization can be accomplished by either carotid endarterectomy (CEA) or carotid artery stenting (CAS), with equally robust evidence in isolated symptomatic carotid stenosis. ${ }^{37}$ No prospective 


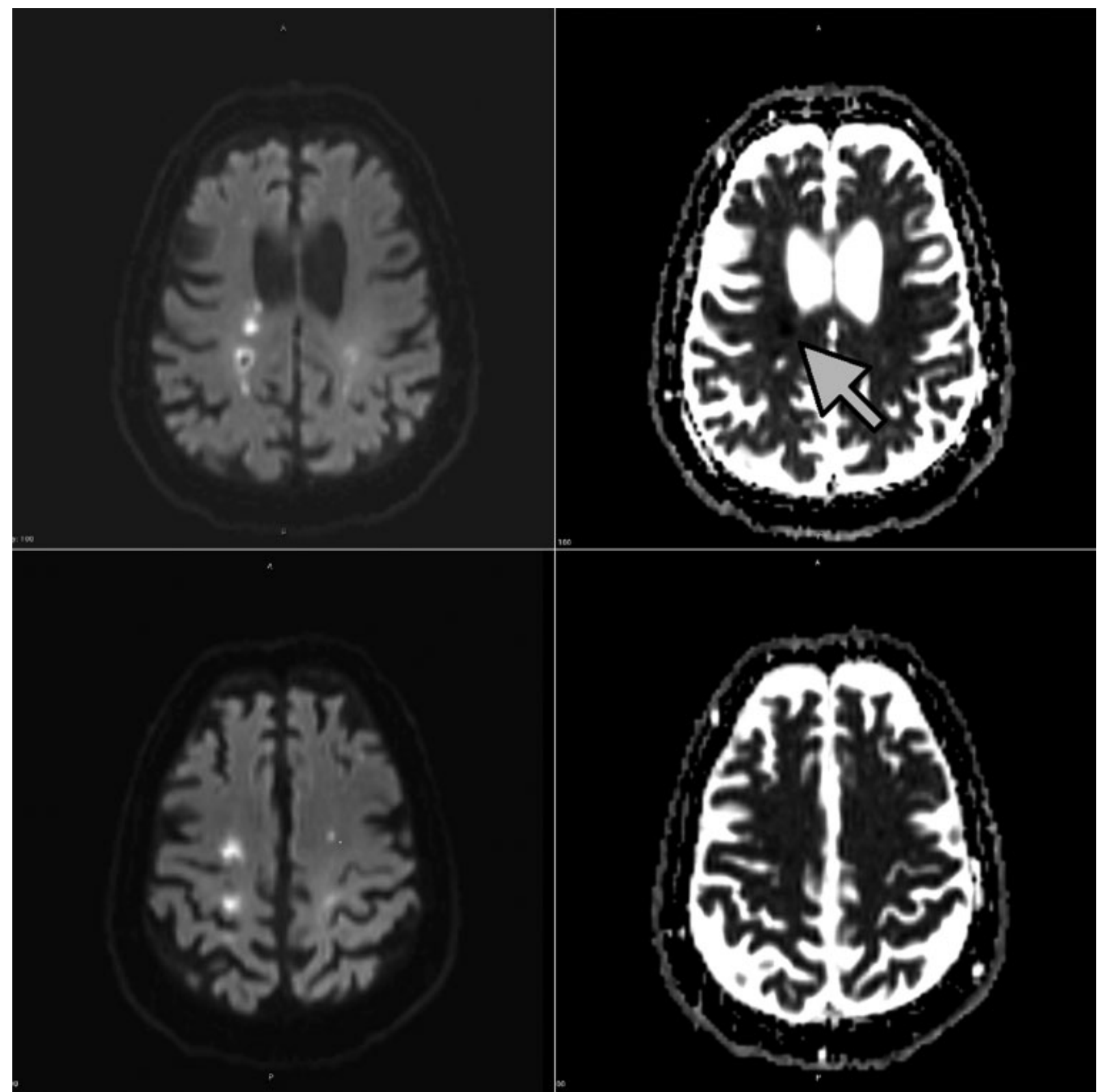

Fig. 3 A 73-year-old man reported mild left arm weakness and numbness immediately after percutaneous coronary intervention for a non-ST elevation myocardial infarction. He had known bilateral internal carotid artery stenosis, graded as $>70 \%$ on the right and 50 to $69 \%$ on the left by ultrasound criteria. Note the classic "string of pearls" pattern of infarcts in the bilateral deep watershed zones seen on diffusion-weighted sequence (left). Also note that only some of the lesions demonstrate hypointensity on apparent diffusion coefficient sequence (right, arrow), indicating that not all are acute.

Table 2 Uncommon causes of strokes following cardiac procedures

Air embolism from cardiopulmonary bypass and vascular
access

Paradoxical embolism from deep vein thrombosis in patients with patent foramen ovale or atrial septal defect

Extracranial cervical artery dissection resulting from hyperextension of the neck during induction of anesthesia

latrogenic aortic dissection with extension into the common carotid arteries

Hemorrhagic stroke resulting from intraoperative heparin bolus studies have compared these two procedures in patients undergoing planned cardiac procedures such as CABG. The timing of carotid revascularization and CABG may be simultaneous, staged (carotid before $C A B G$ ), or reverse staged (carotid after CABG). Meta-analyses of observational comparisons of staged versus simultaneous CEA or CAS with CABG do not clearly favor either timing strategy, and it should be noted that these studies included predominantly asymptomatic carotid stenosis and may be affected by inherent selection bias. ${ }^{38-41}$ One consideration is that following CAS, most clinicians will recommend at least 30 days of uninterrupted dual-antiplatelet therapy to prevent in-stent thrombosis. Therefore, the decision to 
Table 3 Risk factors for strokes following cardiac procedures ${ }^{a}$

\begin{tabular}{|c|c|}
\hline $\begin{array}{l}\text { Risk factors } \\
\text { common to all } \\
\text { procedures }^{b}\end{array}$ & $\begin{array}{l}\text { Older age } \\
\text { Female sex } \\
\text { Previous stroke or TIA } \\
\text { Systolic dysfunction } \\
\text { Renal disease } \\
\text { Underweight or low body surface } \\
\text { area } \\
\text { Left main stem coronary disease } \\
\text { Emergency presentation with acute } \\
\text { coronary syndrome } \\
\text { (nonelective case) } \\
\text { Carotid stenosis } \\
\text { Chronic obstructive pulmonary } \\
\text { disease } \\
\text { Blood transfusion }{ }^{113} \\
\text { POAF }\end{array}$ \\
\hline $\begin{array}{l}\text { Risk factors } \\
\text { specific to } \\
\text { CABG }^{2-4,6,19,28,32,33,114}\end{array}$ & $\begin{array}{l}\text { Non-white race } \\
\text { Preoperative atrial fibrillation } \\
\text { Peripheral vascular disease } \\
\text { Diabetes } \\
\text { Hypertension } \\
\text { Atherosclerosis of the ascending } \\
\text { aorta } \\
\text { On-pump CABG } \\
\text { Hypothermic circulatory arrest } \\
\text { Prolonged cardiopulmonary bypass } \\
\text { and aortic cross-clamp time } \\
\text { Previous cardiac surgery } \\
\text { Preoperative infection } \\
\text { Combined procedures } \\
\text { Postoperative thrombocytopenia }\end{array}$ \\
\hline $\begin{array}{l}\text { Risk factors } \\
\text { specific to } \\
\mathrm{PCl}^{5,9,26,27,115,116}\end{array}$ & $\begin{array}{l}\mathrm{PCl} \text { of an existing bypass graft } \\
\text { Hemodynamic instability } \\
\text { Intra-aortic balloon pump placement } \\
\text { Triple vessel disease } \\
\text { Presence of coronary arterial } \\
\text { thrombus } \\
\text { Valvular disease }\end{array}$ \\
\hline $\begin{array}{l}\text { Risk factors } \\
\text { specific to } \\
\text { TAVI }^{17,117,118}\end{array}$ & $\begin{array}{l}\text { More severe baseline aortic } \\
\text { regurgitation } \\
\text { Multiple device implantation } \\
\text { attempts } \\
\text { Dislodgement of TAVI prosthesis }\end{array}$ \\
\hline
\end{tabular}

Abbreviations: $C A B G$, coronary artery bypass graft; MVR, mitral valve repair; $\mathrm{PCl}$, percutaneous coronary intervention; POAF, postoperative atrial fibrillation; TAVI, transcatheter aortic valve implantation; TIA, transient ischemic attack.

${ }^{\mathrm{a}}$ The most consistently reported risk factors are in bold.

beferences are listed separately below for each procedure.

consider CAS versus CEA before CABG requires multidisciplinary discussion. In cases where revascularization is not performed, whether due to patient-specific factors in individuals with carotid stenosis or to lesions in other locations such as intracranial arterial stenoses, it is reasonable to take precautions including avoidance of significant hypotension intraoperatively, such as by setting a threshold MAP $>70 \mathrm{~mm} \mathrm{Hg}$.

\section{Risk Factors: Atrial Fibrillation}

Atrial fibrillation is encountered in the periprocedural period as either preexisting or new onset following the procedure, and the distinction is important for etiological attribution and management considerations.
In patients undergoing $\mathrm{CABG}$, preexisting $\mathrm{AF}$ increases the risk of perioperative stroke. ${ }^{2,4}$ The type of procedure and individual thromboembolic risk must be accounted for in periprocedural antithrombotic planning. It is necessary to hold oral anticoagulation for at least several days preoperatively prior to open cardiac surgeries. Major guidelines recommend holding warfarin 5 days before major surgery with high bleeding risk, including cardiac surgeries. ${ }^{42-44}$ Bridging with low-molecular-weight heparin or unfractionated heparin should be considered for those with high thromboembolic risk, for example, those with $\mathrm{CHADS}_{2}$ score of 5 or $6 .{ }^{42,43}$ For patients on direct oral anticoagulants with normal renal function, it is recommended to hold for 48 hours before a major surgery. ${ }^{42,43}$ This duration would need to be longer in patients with reduced renal function, depending on the pharmacokinetics of each specific agent. Bridging is not indicated for direct oral anticoagulants. Although no precise recommendations are made in major guidelines regarding continuation of anticoagulation for percutaneous procedures, retrospective evidence suggests that continuous oral anticoagulant use is relatively safe in $\mathrm{PCI}$ and $\mathrm{AF}$ ablation. ${ }^{44-46}$

New-onset POAF is an important cause of perioperative stroke. It is a morbid condition independently associated with perioperative stroke in most, but not all, studies of CABG $^{19,32,47-51}$ and in both PCI and TAVI. ${ }^{35,52}$ Furthermore, POAF has adverse hemodynamic effects, is associated with higher in-hospital mortality and increased duration of hospitalization, and is a predictor of stroke occurring in the years after CABG. ${ }^{49,53-55}$ POAF occurs due to multiple factors including electrolyte imbalance, catecholamine release, atrial ischemia, and pericardial inflammation. ${ }^{56}$ Predictors of new-onset POAF are listed in - Table 4. The rate of POAF is as high as $65 \%$ after combined $C A B G$ and valve surgery. ${ }^{57,58}$ Incidence is moderate after isolated CABG, ranging from 18.0 to $29.5 \%,{ }^{53,57}$ lower after TAVI $(6-11 \%),{ }^{35,52}$ and quite low (0.1-6\%) after PCI. ${ }^{35,52,53}$ Newonset $\mathrm{AF}$ can also occur as a complication of patent foramen ovale closure for secondary stroke prevention, with an

Table 4 Predictors of new-onset postoperative atrial fibrillation

\begin{tabular}{|l|}
\hline Increasing age \\
\hline Male sex \\
\hline Obesity \\
\hline Preoperative heart failure \\
\hline Combined CABG and valve surgery \\
\hline Perioperative $\beta$-blockade \\
\hline Higher positive fluid balance on postoperative days 0-2 \\
\hline Increased white blood cell count postoperatively \\
\hline Increased serum creatinine postoperatively \\
\hline Low serum phosphate postoperatively \\
\hline Higher serum magnesium postoperatively \\
\hline Higher serum C-reactive protein postoperatively \\
\hline
\end{tabular}

Abbreviation: CABG, coronary artery bypass graft. 
incidence of 0.4 to $5.0 \%{ }^{59-62}$ Current guidelines recommend the use of $\beta$-blockers as first-line primary prophylaxis for the development of POAF in patients undergoing CABG. ${ }^{35}$ While studies have demonstrated the efficacy of $\beta$-blockers and antiarrhythmics in the prevention of POAF, a decreased risk of perioperative stroke has not been proven. ${ }^{63}$

Left atrial appendage ligation (LAAL) is frequently performed during cardiac surgical procedures in patients with preexisting AF, with the goal of long-term stroke prevention. A meta-analysis of mostly observational studies consisting of more than 280,000 patients showed significant reductions in both perioperative and long-term stroke risk, with a relative risk of 0.66 and 0.67 , respectively. ${ }^{64}$ However, two large retrospective cohort studies suggest that this intervention may increase the risk of POAF, though they did not demonstrate an increased risk of perioperative stroke. ${ }^{65,66} \mathrm{~A}$ large randomized controlled trial is underway and is expected to complete follow-up in $2022 .^{67}$

\section{Monitoring}

There are multiple methods of monitoring for hypoperfusion or emboli during cardiac surgery, including near-infrared spectroscopy (NIRS), electroencephalography (EEG), and transcranial Doppler ultrasonography (TCD). Although these intraoperative monitoring techniques have some supportive evidence, they have not achieved widespread usage.

NIRS uses light emitted from a probe to evaluate the mixed (arterial and venous vessels $<1 \mathrm{~mm}$ in diameter) vascular oxygen saturation by taking advantage of differing absorption spectra of oxyhemoglobin and deoxyhemoglobin. A systematic review of randomized controlled trials by Serraino and Murphy showed that the use of a NIRS-based protocol did not have any effect on the risk of stroke in cardiac surgery patients, with a relative risk of 1.08 (95\% CI: $0.40-2.91) .{ }^{68}$

EEG can also be used during cardiac surgery, and while EEG changes may be somewhat specific for acute brain injury in the setting of normal baseline EEG and stable anesthesia, EEG requires live expert interpretation to be clinically useful to detect intraoperative stroke and is not sensitive. ${ }^{69}$

TCD can be used to either monitor cerebral blood flow or for the detection of microembolic signals. TCD detects cerebral microemboli as high-intensity transient signals (HITS). These microemboli indicate higher risk of concomitant macroemboli which may cause clinical stroke. The embolic risk related to TAVI has been confirmed by TCD in a study by Kahlert et al, wherein intraprocedural HITS were observed in $100 \%$ of 83 patients undergoing TAVI, and these primarily occurred during manipulation of the calcified aortic valve. ${ }^{70}$ HITS should be interpreted with some caution, however, as they may be caused by air microbubbles rather than microemboli. This is particularly notable during PCI. Bladin et al showed that $70 \%$ of HITS during PCI occurred during injection of saline or contrast, ${ }^{71}$ rather than during maneuvers (such as catheter manipulation), which would be expected to cause embolic phenomena.

Postoperatively, monitoring should include continuous cardiac telemetry, particularly after CABG and open valve replacements, after which the risk of POAF is highest. Routine neurologic assessments should also be performed by nursing staff to monitor for development of neurologic deficits.

\section{Hyperacute Stroke Management}

If there is a concern for new neurologic deficit potentially representing a stroke after a cardiac procedure, hospitalspecific acute stroke protocols should be activated. These should include neurological examination including the National Institutes of Health Stroke Scale, ${ }^{72}$ confirmation of the time the patient was last known well, blood pressure and blood glucose measurements, and rapid performance of brain and cerebrovascular imaging. In centers without rapid access to stroke-trained personnel, the use of a teleneurology/telestroke system can facilitate rapid evaluation. In most centers, hyperacute imaging is best performed with noncontrast head computed tomography and computed tomographic angiography of the head and neck. In select centers, hyperacute magnetic resonance imaging (MRI) of the brain and magnetic resonance angiography of the head and neck are performed. MRI is generally not possible in the first few days after open cardiac surgeries, during which non-MRI-compatible pacing wires are frequently present.

Treatment options for suspected hyperacute stroke include thrombolysis and thrombectomy.

The AHA/ASA 2018 guidelines for the early management of acute ischemic stroke state that intravenous "alteplase is reasonable for the treatment of AIS [acute ischemic stroke] complications of cardiac or cerebral angiographic procedures, depending on the usual eligibility criteria."73 Recent major surgery and coagulopathy are contraindications to intravenous thrombolysis, and most vascular neurologists would consider the risk of surgical site hemorrhage to outweigh potential benefit in the postoperative period after sternotomy. However, after percutaneous procedures, the risk of surgical site bleeding is lower, and intravenous thrombolysis can be considered. ${ }^{74}$ The safety of thrombolysis in patients who present with strokes after cardiac catheterization was examined in a 2008 multicenter retrospective cohort study, in which outcomes in the 12 treated patients ( 7 intravenous and 5 intra-arterial) compared favorably with the 54 untreated patients. ${ }^{75}$ It is important to keep in mind that heparinoids are frequently administered during cardiac catheterization, and after heparin administration intravenous thrombolysis should be given only if the prothrombin time has normalized. Although none of the three patients in the aforementioned cohort who were treated despite prothrombin times over 40 seconds developed a hemorrhagic complication, the AHA/ASA guidelines recommend against the use of intravenous alteplase in patients with prolonged prothrombin times. ${ }^{73,75}$

Mechanical thrombectomy has been performed in stroke after cardiac surgery ${ }^{73}$ as well as catheter-based procedures, ${ }^{76}$ and can be considered within 24 hours of postoperative stroke onset on a case-by-case basis. Thrombectomy should be considered in patients with occlusions of the intracranial carotid artery, middle cerebral artery M1 segment, and in some cases and centers proximal occlusions of the M2 
branches of the middle cerebral artery. In selected cases, mechanical thrombectomy may be performed for occlusions of the basilar or posterior cerebral arteries. Patients with a large vessel occlusion who are not currently at a thrombectomy-capable center should be transferred immediately to a thrombectomy-capable center. Thrombectomy can be performed in patients with a large vessel occlusion without additional imaging beyond a noncontrast CT (to rule out hemorrhage) if it is within 6 hours of the time last known well. Patients who were last known well 6 to 24 hours before thrombectomy should undergo additional specialized imaging with CT or MR perfusion imaging, and thrombectomy performed if the patients meet the DAWN (6-24hours) ${ }^{77}$ or DEFUSE-3 (6-16 hours) ${ }^{78}$ eligibility criteria. The DAWN criteria require a clinical-imaging mismatch with varying cut-offs for maximum core infarct volume based on age and clinical stroke severity. The DEFUSE-3 criteria require core infarct volume $<70 \mathrm{~mL}$, ratio of ischemic tissue to core infarct of $\geq 1.8$, and penumbra of larger than $15 \mathrm{~mL}$.

\section{Secondary Prevention}

For patients with perioperative stroke and no indication for anticoagulation, antiplatelet therapy is the mainstay of treatment. As long as at least a single antiplatelet agent is administered, it is reasonable to defer the choice of antiplatelet therapy to cardiology/cardiac surgical teams, though risk of hemorrhagic conversion should be weighed against thrombotic risk, particularly if dual-antiplatelet therapy is being considered.

For patients with perioperative stroke and an indication for anticoagulation, the timing of resumption of anticoagulation must be weighed carefully. Risk of recurrent stroke must be balanced against the risk of surgical bleeding and risk of hemorrhagic conversion of the stroke. American and European guidelines recommend restarting anticoagulation for $\mathrm{AF}$ within 14 days of stroke, ${ }^{73,79}$ but the timing of resumption within that 14-day range is unclear. The American Heart Association/American Stroke Association 2018 guideline recommends starting oral anticoagulation between 4 and 14 days after stroke. ${ }^{73}$ The European Heart Rhythm Association provides more concrete guidance based on clinical stroke severity via the National Institutes of Health Stroke Scale score, with recommended oral anticoagulant resumption timelines varying from 1 to 12 days after stroke. ${ }^{79}$ These guideline recommendations are based on observational data and expert opinion; as to date, there have not been large randomized controlled trials addressing this issue. Regardless of the timing of initiation of anticoagulation, for patients with strokes at higher risk of hemorrhagic conversion, it is often prudent to initially use intravenous anticoagulant infusions such as unfractionated heparin rather than oral anticoagulation given the ability to quickly reverse the agent if hemorrhage does occur. If the patient demonstrates clinical and/or imaging stability on intravenous anticoagulation, and with increased time since infarction, clinicians can then consider transitioning to the oral anticoagulant of choice.

Whether or not patients with preoperative AF who undergo LAAL should resume anticoagulation is currently unknown. Exclusion of the left atrial appendage is not always complete, with success rate for occlusion (by postoperative transesophageal echocardiography) ranging from 66 to 95\%. ${ }^{80-82}$

Historically, new-onset POAF was considered a shortterm complication that did not result in serious morbidity or mortality. ${ }^{83}$ While POAF onset peaks on postoperative days 2 to 3 with a median duration of 22 hours, ${ }^{53,57}$ and indeed often is (at least initially) transient with only $2.8 \%$ of POAF patients having persistent AF on discharge, ${ }^{57}$ it is associated with significant long-term consequences.

Butt et al showed in a cohort of patients with left-sided valvular surgery that POAF patients were similarly likely to be initially treated with oral anticoagulants compared with new-onset nonvalvular atrial fibrillation (NVAF) patients, but POAF patients were less likely to still be taking oral anticoagulants at 1 year compared with NVAF patients. ${ }^{84}$ Though they were less likely to be on oral anticoagulants at 1 year, patients with POAF had similar risk of thromboembolism as NVAF (HR: $1.22 ; 95 \% \mathrm{CI}$ : 0.88-1.68). This similar thromboembolic risk is not mediated by recurrent $\mathrm{AF}$, as POAF patients after all types of cardiac surgery had lower risk of recurrent AF compared with NVAF (HR: 0.62; 95\% CI: 0.56-0.70), but the subset of patients who underwent mitral valve surgery had similar risk of recurrent AF when compared with NVAF patients. ${ }^{84}$ While this discrepancy between rates of recurrent $\mathrm{AF}$ and thromboembolism may represent subclinical short AF events, it is not clear why subclinical events would not be equally prevalent in both groups. It is therefore possible that POAF indicates the presence of an atrial cardiopathy that itself increases thromboembolic risk. ${ }^{85-90}$

Multiple major international guidelines have addressed the question of antithrombotic management of POAF. The American Heart Association/American College of Cardiology/Heart Rhythm Society guidelines state it is reasonable to consider antithrombotic therapy for POAF patients just as would be done for patients with AF of other etiologies. ${ }^{91}$ The European Heart Rhythm Association's guidelines recommend consideration of antithrombotic therapy if the duration of POAF is at least 48 hours. $^{92}$ The Canadian Cardiovascular Society recommends consideration of anticoagulation if POAF lasts at least 72 hours and is present at hospital discharge, and recommends reexamination of the anticoagulation decision at 6 to 12 weeks postoperatively. ${ }^{93}$

\section{Cognitive Complications}

Cardiac surgeries result in both acute and chronic cognitive complications. Both early and late cognitive complications are more common after open cardiac surgeries, though they can occur in catheter-based procedures as well. Early postoperative cognitive dysfunction is likely caused by contributions from embolism, hypoperfusion injury, blood-brain barrier injury from systemic inflammation, as well as toxic-metabolic encephalopathy and ICU delirium. The presence of late cognitive decline implies that some permanent cerebral injury occurs in the perioperative period. 
The argument for cerebral hypoperfusion as a contributing factor in early perioperative cognitive dysfunction is supported by a study of 92 patients by Siepe et al. ${ }^{94}$ This study showed that increased systemic perfusion pressure (mean arterial pressure of 80-90 compared with 60-70) during cardiopulmonary bypass was associated with reduced risk of postoperative delirium. This association was present despite a lack of difference between groups in intraoperative cerebral oxygenation as measured by NIRS. Another putative causative factor, systemic inflammation, has been demonstrated postoperatively, ${ }^{58,95}$ but there are currently no treatments that have consistently shown benefit on this mechanism.

There is some limited evidence for modulating sympathetic activity in preventing acute cognitive dysfunction after cardiac surgery; perioperative dexmedetomidine was shown to be beneficial in reducing postoperative delirium (adjusted OR: 0.350; 95\% CI, 0.212-0.578). ${ }^{96}$

Embolic ischemic cerebral injury is a clear contributor to both acute and chronic neurocognitive dysfunction. Embolicappearing diffusion-restricting brain lesions on MRI are very common after cardiac procedures, particularly after CABG and valve surgeries (both open and transcatheter). The incidence of new cerebral ischemic lesions on MRI ranges from 31 to $40 \%^{97-99}$ after open cardiac surgery, and as high as $90 \%$ after TAVI. ${ }^{100}$ Barber et al showed cognitive dysfunction at 5 days and 6 weeks postoperatively in 15 of 15 patients with new ischemic brain lesions (the majority of which were silent) versus only 6 of 17 patients without new ischemic lesions $(p<0.001) .{ }^{97}$

While silent ischemic lesions are associated with cognitive decline, intraoperative embolic signals detected by TCD have not been similarly correlated with early cognitive dysfunction; however, they may play a greater role in chronic cognitive dysfunction. Using intraoperative TCD microembolic signals, Liu et al showed that microembolic signals were reduced from a median of 430 to 2 when comparing surgery with cardiopulmonary bypass and off-pump surgery, but there was no difference in the incidence of postoperative cognitive dysfunction between the two surgical techniques at either 1 week or 3 months. ${ }^{101}$ This lack of early difference with microemboli reduction with OPCABG was corroborated in a similar study by Stroobant et al, ${ }^{102}$ though the off-pump group demonstrated cognitive impairment on fewer neuropsychological tests 6 months postoperatively.

Silent cerebral microbleeds have also been identified postoperatively after cardiac surgery. A study by Patel et al showed a $24 \%$ incidence of new cerebral microbleeds, and there was a linear association with longer time on cardiopulmonary bypass, but there was no association with cognitive outcomes. ${ }^{99}$

The time course of chronic postoperative cognitive decline raises questions about its mechanisms. There is not only a step-off from baseline cognition after surgery, as would be expected from pure perioperative ischemic injury, but also progressive postsurgical decline. Newman et al performed a battery of neurocognitive tasks at preoperative, in-hospital, 6-week, 6-month, and 5-year time points. In both patients who were and who were not cognitively impaired at discharge, cognition improved postoperatively, peaking at the 6-month time point, and then decreased again at the 5-year time point. Though both groups followed this same general trajectory over time, the group without cognitive decline prior to discharge returned to baseline cognition at 6 months, whereas those with cognitive decline prior to discharge did not. Those with cognitive decline prior to discharge also had a more severe drop in cognition between the 6-month and 5-year evaluations. ${ }^{103}$ It is unclear whether this accelerated cognitive decline seen in some patients post-cardiac surgery reflects the presence of an underlying neurodegenerative disorder, or whether the surgery itself unmasks or accelerates cognitive decline. This determination is confounded by the presence of vascular risk factors, which are prevalent in both patient populations who undergo cardiac surgery and those who develop dementia. There are currently no large studies with appropriate control arms to determine whether the rate of progressive cognitive decline after cardiac surgery is different than would be expected in this patient population with vascular risk factors.

Lastly, it is possible that for some patients, improved cerebral blood flow and quality of life may in fact contribute to better cognitive function after cardiac procedures. One prospective cohort study trended an extensive battery of cognitive tests in 51 patients undergoing TAVI and found an average improvement in the cognitive status persisting at 1 year, though unfortunately no imaging data were available to correlate individual cognitive trajectories with silent ischemic lesions. ${ }^{104}$

\section{Other Neurological Complications of Cardiac Procedures}

\section{Contrast-Induced Encephalopathy}

Contrast-induced encephalopathy is a rare but well-recognized complication of cardiac catheterization and other angiographic procedures. Symptom onset is within minutes to hours of iodinated contrast exposure, and can include any combination of headache, encephalopathy, cortical blindness and other focal cortical symptoms, and seizure. Risk factors include renal disease, higher contrast load, and the use of older, ionic, high osmolarity contrast preparations. Neuroimaging may be normal or may show vasogenic edema and cortical contrast enhancement with a posterior predilection. The pathophysiology of contrast-induced encephalopathy involves endothelial dysfunction and failure of autoregulation. This pathophysiology has a high degree of overlap with the posterior reversible encephalopathy syndrome (PRES). Like PRES, contrast-induced encephalopathy is usually fully reversible within days with supportive management alone. ${ }^{105,106}$

\section{Seizures}

Seizures may rarely be provoked in the setting of cardiac procedures by a variety of factors such as acute stroke, medications, contrast-induced encephalopathy, or hypoxic brain injury. Furthermore, patients with preexisting epilepsy may experience breakthrough seizures in the postprocedural period. In a large single-center study of consecutive CABG cases, postoperative seizures occurred in $0.95 \%$ of patients. 
Median time of first seizure from the completion of surgery was 6 hours, 59\% were generalized, and $14.5 \%$ were associated with a new stroke on imaging. Seizures were associated with longer ICU stays and higher ICU mortality. ${ }^{107}$ Nonconvulsive seizures, including nonconvulsive status epilepticus, should be considered when evaluating patients who do not awake after cardiac surgery. In these patients, EEG evaluation is critical, ideally by performing 24 hours of continuous EEG monitoring to rule out intermittent nonconvulsive seizures.

One important cause of provoked seizures in patients undergoing open cardiac surgeries is the use of high-dose tranexamic acid, an antifibrinolytic medication with known dose-related proconvulsant properties. In the Aspirin and Tranexamic Acid for Coronary Artery Surgery trial, patients undergoing $\mathrm{CABG}$ who were randomized to receive 50 to $100 \mathrm{mg} / \mathrm{kg}$ of tranexamic acid were 7.6 times more likely to have a postoperative seizure compared with the placebo group, with a number needed to harm of $177 . .^{108}$

Seizures following cardiac procedures, especially open cardiac surgeries, should be aggressively treated with antiseizure medications, which should be continued for at least the postoperative period, and longer depending on underlying cause.

\section{Conclusion}

Neurologic complications, particularly acute ischemic stroke and encephalopathy, are common after cardiac procedures. Neurologists play an important role in diagnosing, treating, and directing secondary prevention strategies for these conditions, and should maintain familiarity with both common and uncommon complications of cardiac procedures. Given the complexity of these complications and the heterogeneity of available evidence, it is important to individualize each patient's management plan and coordinate multidisciplinary communication to ensure optimal patient care.

\section{Conflict of Interest}

None declared.

\section{References}

1 Head SJ, Milojevic M, Daemen J, et al. Stroke rates following surgical versus percutaneous coronary revascularization. J Am Coll Cardiol 2018;72(04):386-398

2 Moreyra AE, Maniatis GA, Gu H, et al; Myocardial Infarction Data Acquisition System (MIDAS 28) Study Group. Frequency of stroke after percutaneous coronary intervention or coronary artery bypass grafting (from an eleven-year statewide analysis). Am J Cardiol 2017;119(02):197-202

3 Bucerius J, Gummert JF, Borger MA, et al. Stroke after cardiac surgery: a risk factor analysis of 16,184 consecutive adult patients. Ann Thorac Surg 2003;75(02):472-478

4 McKhann GM, Grega MA, Borowicz LM Jr, Baumgartner WA, Selnes OA. Stroke and encephalopathy after cardiac surgery: an update. Stroke 2006;37(02):562-571

5 Wong SC, Minutello R, Hong MK. Neurological complications following percutaneous coronary interventions (a report from the 2000-2001 New York State Angioplasty Registry). Am J Cardiol 2005;96(09):1248-1250
6 Tarakji KG, Sabik JF III, Bhudia SK, Batizy LH, Blackstone EH. Temporal onset, risk factors, and outcomes associated with stroke after coronary artery bypass grafting. JAMA 2011;305(04):381-390

7 Kowalewski M, Pawliszak W, Malvindi PG, et al. Off-pump coronary artery bypass grafting improves short-term outcomes in high-risk patients compared with on-pump coronary artery bypass grafting: meta-analysis. J Thorac Cardiovasc Surg 2016; 151(01):60-77.e1, 58

8 Gaudino M, Angelini GD, Antoniades C, et al; Arterial Grafting International Consortium (ATLANTIC) Alliance. Off-pump coronary artery bypass grafting: 30 years of debate. J Am Heart Assoc 2018;7(16):e009934

9 Korn-Lubetzki I, Farkash R, Pachino RM, Almagor Y, Tzivoni D, Meerkin D. Incidence and risk factors of cerebrovascular events following cardiac catheterization. J Am Heart Assoc 2013;2(06): e000413

10 Leon MB, Smith CR, Mack M, et al; PARTNER Trial Investigators. Transcatheter aortic-valve implantation for aortic stenosis in patients who cannot undergo surgery. N Engl J Med 2010;363 (17):1597-1607

11 Smith CR, Leon MB, Mack MJ, et al; PARTNER Trial Investigators. Transcatheter versus surgical aortic-valve replacement in highrisk patients. N Engl J Med 2011;364(23):2187-2198

12 Shah K, Chaker Z, Busu T, et al. Meta-analysis comparing the frequency of stroke after transcatheter versus surgical aortic valve replacement. Am J Cardiol 2018;122(07):1215-1221

13 Mohananey D, Sankaramangalam K, Kumar A, et al. Safety and efficacy of cerebral protection devices in transcatheter aortic valve replacement: a clinical end-points meta-analysis. Cardiovasc Revasc Med 2018;19(7, Pt A):785-791

14 Cho S-M, Deshpande A, Pasupuleti V, Hernandez AV, Uchino K. Radiographic and clinical brain infarcts in cardiac and diagnostic procedures: a systematic review and meta-analysis. Stroke 2017;48(10):2753-2759

15 Likosky DS, Marrin CAS, Caplan LR, et al; Northern New England Cardiovascular Disease Study Group. Determination of etiologic mechanisms of strokes secondary to coronary artery bypass graft surgery. Stroke 2003;34(12):2830-2834

16 Nishiyama K, Horiguchi M, Shizuta S, et al. Temporal pattern of strokes after on-pump and off-pump coronary artery bypass graft surgery. Ann Thorac Surg 2009;87(06):1839-1844

17 Kahlert P, Al-Rashid F, Plicht B, et al. Incidence, predictors, origin and prevention of early and late neurological events after transcatheter aortic valve implantation (TAVI): a comprehensive review of current data. J Thromb Thrombolysis 2013;35(04):436-449

18 Guptill JT, Mehta RH, Armstrong PW, et al. Stroke after primary percutaneous coronary intervention in patients with ST-segment elevation myocardial infarction: timing, characteristics, and clinical outcomes. Circ Cardiovasc Interv 2013;6(02):176-183

19 Hogue CW Jr, Murphy SF, Schechtman KB, Dávila-Román VG. Risk factors for early or delayed stroke after cardiac surgery. Circulation 1999;100(06):642-647

20 Van Mieghem NM, El Faquir N, Rahhab Z, et al. Incidence and predictors of debris embolizing to the brain during transcatheter aortic valve implantation. JACC Cardiovasc Interv 2015;8(05): 718-724

21 Walker BS, Shah LM, Osborn AG. Calcified cerebral emboli, a "do not miss" imaging diagnosis: 22 new cases and review of the literature. AJNR Am J Neuroradiol 2014;35(08):1515-1519

22 Kronzon I, Saric M. Cholesterol embolization syndrome. Circulation 2010;122(06):631-641

23 Ozkok A. Cholesterol-embolization syndrome: current perspectives. Vasc Health Risk Manag 2019;15:209-220

24 Masabni K, Raza S, Blackstone EH, Gornik HL, Sabik JF III. Does preoperative carotid stenosis screening reduce perioperative stroke in patients undergoing coronary artery bypass grafting? J Thorac Cardiovasc Surg 2015;149(05):1253-1260 
25 Naylor AR, Mehta Z, Rothwell PM, Bell PRF. Reprinted article "carotid artery disease and stroke during coronary artery bypass: a critical review of the literature". Eur J Vasc Endovasc Surg 2011;42(Suppl 1):S73-S83

26 Fuchs S, Stabile E, Kinnaird TD, et al. Stroke complicating percutaneous coronary interventions: incidence, predictors, and prognostic implications. Circulation 2002;106(01):86-91

27 Kwok CS, Kontopantelis E, Myint PK, et al; British Cardiovascular Intervention Society National Institute for Cardiovascular Outcomes Research. Stroke following percutaneous coronary intervention: type-specific incidence, outcomes and determinants seen by the British Cardiovascular Intervention Society 2007-12. Eur Heart J 2015;36(25):1618-1628

28 Karhausen JA, Smeltz AM, Akushevich I, et al. Platelet counts and postoperative stroke after coronary artery bypass grafting surgery. Anesth Analg 2017;125(04):1129-1139

29 Pawliszak W, Kowalewski M, Raffa GM, et al. Cerebrovascular events after no-touch off-pump coronary artery bypass grafting, conventional side-clamp off-pump coronary artery bypass, and proximal anastomotic devices: a meta-analysis. J Am Heart Assoc 2016;5(02):e002802

30 Takagi H, Hari Y, Mitta S, Kawai N, Ando TALICE (All-Literature Investigation of Cardiovascular Evidence) Group. A meta-analysis of $\geq 5$-year mortality in randomized controlled trials of offpump versus on-pump coronary artery bypass grafting. J Card Surg 2018;33(11):716-724

31 Smart NA, Dieberg G, King N. Long-term outcomes of on- versus off-pump coronary artery bypass grafting. J Am Coll Cardiol 2018;71(09):983-991

32 Hornero F, Martín E, Rodríguez R, et al; Working Group on Arrhythmia Surgery and Cardiac Pacing of the Spanish Society for Cardiovascular and Thoracic Surgery (SECTCV) A multicentre Spanish study for multivariate prediction of perioperative inhospital cerebrovascular accident after coronary bypass surgery: the PACK2 score. Interact Cardiovasc Thorac Surg 2013;17(02): 353-358, discussion 358

33 Charlesworth DC, Likosky DS, Marrin CAS, et al; Northern New England Cardiovascular Disease Study Group. Development and validation of a prediction model for strokes after coronary artery bypass grafting. Ann Thorac Surg 2003;76(02):436-443

34 European Carotid Surgery Trialists' Collaborative Group. Randomised trial of endarterectomy for recently symptomatic carotid stenosis: final results of the MRC European Carotid Surgery Trial (ECST). Lancet 1998;351(9113):1379-1387

35 Sousa-Uva M, Neumann F-J, Ahlsson A, et al; ESC Scientific Document Group. 2018 ESC/EACTS Guidelines on myocardial revascularization. Eur J Cardiothorac Surg 2019;55(01):4-90

36 Hillis LD, Smith PK, Anderson JL, et al. 2011 ACCF/AHA guideline for coronary artery bypass graft surgery: executive summary: a report of the American College of Cardiology Foundation/American Heart Association Task Force on Practice Guidelines. Circulation 2011;124(23):2610-2642

37 Brott TG, Hobson RW II, Howard G, et al; CREST Investigators. Stenting versus endarterectomy for treatment of carotid-artery stenosis. N Engl J Med 2010;363(01):11-23

38 Sharma V, Deo SV, Park SJ, Joyce LD. Meta-analysis of staged versus combined carotid endarterectomy and coronary artery bypass grafting. Ann Thorac Surg 2014;97(01):102-109

39 Giannopoulos S, Texakalidis P, Charisis N, et al. Synchronous carotid endarterectomy and coronary artery bypass graft versus staged carotid artery stenting and coronary artery bypass graft for patients with concomitant severe coronary and carotid stenosis: a systematic review and meta-analysis. Ann Vasc Surg 2020;62:463-473.e4

40 Paraskevas KI, Nduwayo S, Saratzis AN, Naylor AR. Carotid stenting prior to coronary bypass surgery: an updated systematic review and meta-analysis. Eur J Vasc Endovasc Surg 2017;53 (03):309-319
41 Zhang J, Xu RW, Fan X, Ye Z, Liu P. A systematic review of early results following synchronous or staged carotid artery stenting and coronary artery bypass grafting. Thorac Cardiovasc Surg 2017;65(04):302-310

42 Douketis JD, Spyropoulos AC, Spencer FA, et al. Perioperative management of antithrombotic therapy: Antithrombotic Therapy and Prevention of Thrombosis, 9th ed: American College of Chest Physicians Evidence-Based Clinical Practice Guidelines. Chest 2012;141(2, Suppl):e326S-e350S

43 Hornor MA, Duane TM, Ehlers AP, et al. American College of Surgeons' guidelines for the perioperative management of antithrombotic medication. J Am Coll Surg 2018;227(05):521-536.e1

44 Doherty JU, Gluckman TJ, Hucker WJ, et al. 2017 ACC Expert Consensus Decision Pathway for periprocedural management of anticoagulation in patients with nonvalvular atrial fibrillation: a report of the American College of Cardiology Clinical Expert Consensus Document Task Force. J Am Coll Cardiol 2017;69(07): 871-898

45 Jamula E, Lloyd NS, Schwalm JD, Airaksinen KEJ, Douketis JD. Safety of uninterrupted anticoagulation in patients requiring elective coronary angiography with or without percutaneous coronary intervention: a systematic review and metaanalysis. Chest 2010;138(04):840-847

46 Ha FJ, Barra S, Brown AJ, Begley DA, Grace AA, Agarwal S. Continuous and minimally-interrupted direct oral anticoagulant are both safe compared with vitamin $\mathrm{K}$ antagonist for atrial fibrillation ablation: an updated meta-analysis. Int J Cardiol 2018;262:51-56

47 Stamou SC, Dangas G, Hill PC, et al. Atrial fibrillation after beating heart surgery. Am J Cardiol 2000;86(01):64-67

48 Lahtinen J, Biancari F, Salmela E, et al. Postoperative atrial fibrillation is a major cause of stroke after on-pump coronary artery bypass surgery. Ann Thorac Surg 2004;77(04):1241-1244

49 Villareal RP, Hariharan R, Liu BC, et al. Postoperative atrial fibrillation and mortality after coronary artery bypass surgery. J Am Coll Cardiol 2004;43(05):742-748

50 Likosky DS, Caplan LR, Weintraub RM, et al; Northern New England Cardiovascular Disease Study Group, Lebanon, New Hampshire. Intraoperative and postoperative variables associated with strokes following cardiac surgery. Heart Surg Forum 2004;7(04):E271-E276

51 Lotfi A, Wartak S, Sethi P, Garb J, Giugliano GR. Postoperative atrial fibrillation is not associated with an increased risk of stroke or the type and number of grafts: a single-center retrospective analysis. Clin Cardiol 2011;34(12):787-790

52 Mojoli M, Gersh BJ, Barioli A, et al. Impact of atrial fibrillation on outcomes of patients treated by transcatheter aortic valve implantation: a systematic review and meta-analysis. Am Heart J 2017;192:64-75

53 Kosmidou I, Chen S, Kappetein AP, et al. New-onset atrial fibrillation after PCI or CABG for left main disease: the EXCEL trial. J Am Coll Cardiol 2018;71(07):739-748

54 Gialdini G, Nearing K, Bhave PD, et al. Perioperative atrial fibrillation and the long-term risk of ischemic stroke. JAMA 2014;312(06):616-622

55 Megens MR, Churilov L, Thijs V. New-onset atrial fibrillation after coronary artery bypass graft and long-term risk of stroke: a meta-analysis. J Am Heart Assoc 2017;6(12):e007558

56 Burke SW, Solomon AJ. Atrial fibrillation in patients after cardiovascular surgery: incidence, risk factors, preventive and therapeutic strategies. Am J Cardiovasc Drugs 2003;3(02):95-100

57 Filardo G, Damiano RJ Jr, Ailawadi G, et al. Epidemiology of newonset atrial fibrillation following coronary artery bypass graft surgery. Heart 2018;104(12):985-992

58 Greenberg JW, Lancaster TS, Schuessler RB, Melby SJ. Postoperative atrial fibrillation following cardiac surgery: a persistent complication. Eur J Cardiothorac Surg 2017;52(04):665-672 
59 Saver JL, Carroll JD, Thaler DE, et al; RESPECT Investigators. Longterm outcomes of patent foramen ovale closure or medical therapy after stroke. N Engl J Med 2017;377(11):1022-1032

60 Mas JL, Derumeaux G, Guillon B, et al; CLOSE Investigators. Patent foramen ovale closure or anticoagulation vs. antiplatelets after stroke. N Engl J Med 2017;377(11):1011-1021

61 Turc G, Calvet D, Guérin P, Sroussi M, Chatellier G, Mas JLCLOSE Investigators. Closure, anticoagulation, or antiplatelet therapy for cryptogenic stroke with patent foramen ovale: systematic review of randomized trials, sequential meta-analysis, and new insights from the CLOSE study. J Am Heart Assoc 2018;7(12): e008356

62 Smer A, Salih M, Mahfood Haddad T, et al. Meta-analysis of randomized controlled trials on patent foramen ovale closure versus medical therapy for secondary prevention of cryptogenic stroke. Am J Cardiol 2018;121(11):1393-1399

63 Arsenault KA, Yusuf AM, Crystal E, et al. Interventions for preventing post-operative atrial fibrillation in patients undergoing heart surgery. Cochrane Database Syst Rev 2013;(01): CD003611

64 Gutierrez EM, Castano M, Gualis J, et al. Beneficial effect of left atrial appendage closure during cardiac surgery: a meta-analysis of 280585 patients. Eur J Cardiothorac Surg 2020;57(02):252-262

65 Melduni RM, Schaff HV, Lee HC, et al. Impact of left atrial appendage closure during cardiac surgery on the occurrence of early postoperative atrial fibrillation, stroke, and mortality: a propensity score-matched analysis of 10633 patients. Circulation 2017;135(04):366-378

66 Yao X, Gersh BJ, Holmes DR Jr, et al. Association of surgical left atrial appendage occlusion with subsequent stroke and mortality among patients undergoing cardiac surgery. JAMA 2018;319 (20):2116-2126

67 Whitlock R, Healey J, Vincent J, et al. Rationale and design of the Left Atrial Appendage Occlusion Study (LAAOS) III. Ann Cardiothorac Surg 2014;3(01):45-54

68 Serraino GF, Murphy GJ. Effects of cerebral near-infrared spectroscopy on the outcome of patients undergoing cardiac surgery: a systematic review of randomised trials. BMJ Open 2017;7(09): e016613

69 Billard V. Brain injury under general anesthesia: is monitoring of the EEG helpful? Can J Anaesth 2001;48(11):1055-1060

70 Kahlert P, Al-Rashid F, Döttger P, et al. Cerebral embolization during transcatheter aortic valve implantation: a transcranial Doppler study. Circulation 2012;126(10):1245-1255

71 Bladin CF, Bingham L, Grigg L, Yapanis AG, Gerraty R, Davis SM. Transcranial Doppler detection of microemboli during percutaneous transluminal coronary angioplasty. Stroke 1998;29(11): 2367-2370

72 The National Institute of Neurological Disorders and Stroke rt-PA Stroke Study Group. Tissue plasminogen activator for acute ischemic stroke. N Engl J Med 1995;333:1581-1587

73 Powers WJ, Rabinstein AA, Ackerson T, et al; American Heart Association Stroke Council. 2018 Guidelines for the early management of patients with acute ischemic stroke: a guideline for healthcare professionals from the American Heart Association/ American Stroke Association. Stroke 2018;49(03):e46-e110

74 Madeira M, Martins C, Koukoulis G, Marques M, Reis J, Abecassis M. Mechanical thrombectomy for stroke after cardiac surgery. J Card Surg 2016;31(08):517-520

75 Khatri P, Taylor RA, Palumbo V, et al; Treatment of Acute Stroke after Cardiac Catheterization (TASCC) Study Group. The safety and efficacy of thrombolysis for strokes after cardiac catheterization. J Am Coll Cardiol 2008;51(09):906-911

76 D'Anna L, Demir O, Banerjee S, Malik I. Intravenous thrombolysis and mechanical thrombectomy in patients with stroke after TAVI: a report of two cases. J Stroke Cerebrovasc Dis 2019;28 (10):104277
77 Nogueira RG, Jadhav AP, Haussen DC, et al; DAWN Trial Investigators. Thrombectomy 6 to 24 hours after stroke with a mismatch between deficit and infarct. N Engl J Med 2018;378(01): $11-21$

78 Albers GW, Marks MP, Kemp S, et al; DEFUSE 3 Investigators. Thrombectomy for stroke at 6 to 16 hours with selection by perfusion imaging. N Engl J Med 2018;378(08):708-718

79 Heidbuchel H, Verhamme P, Alings M, et al. Updated European Heart Rhythm Association practical guide on the sue of non-vitamin $\mathrm{K}$ antagonist anticoagulants in patients with non-valvular atrial fibrillation: executive summary. Eur Heart J 2013;34:2094-2106

80 Healey JS, Crystal E, Lamy A, et al. Left Atrial Appendage Occlusion Study (LAAOS): results of a randomized controlled pilot study of left atrial appendage occlusion during coronary bypass surgery in patients at risk for stroke. Am Heart J 2005;150(02): 288-293

81 Zapolanski A, Johnson CK, Dardashti O, et al. Epicardial surgical ligation of the left atrial appendage is safe, reproducible, and effective by transesophageal echocardiographic follow-up. Innovations (Phila) 2013;8(05):371-375

82 García-Fernández MA, Pérez-David E, Quiles J, et al. Role of left atrial appendage obliteration in stroke reduction in patients with mitral valve prosthesis: a transesophageal echocardiographic study. J Am Coll Cardiol 2003;42(07):1253-1258

83 Hui DS, Lee R. Treatment of postoperative atrial fibrillation: the long road ahead. J Thorac Cardiovasc Surg 2019

84 Butt JH, Olesen JB, Gundlund A, et al. Long-term thromboembolic risk in patients with postoperative atrial fibrillation after leftsided heart valve surgery. JAMA Cardiol 2019;4(11):1139-1147

85 Cox JL. A perspective of postoperative atrial fibrillation in cardiac operations. Ann Thorac Surg 1993;56(03):405-409

86 Hogue CW Jr, Creswell LL, Gutterman DD, Fleisher LAAmerican College of Chest Physicians. Epidemiology, mechanisms, and risks: American College of Chest Physicians guidelines for the prevention and management of postoperative atrial fibrillation after cardiac surgery. Chest 2005;128(2, Suppl):9S-16S

87 Zaman JAB, Harling L, Ashrafian $\mathrm{H}$, et al. Post-operative atrial fibrillation is associated with a pre-existing structural and electrical substrate in human right atrial myocardium. Int $\mathrm{J}$ Cardiol 2016;220:580-588

88 Goette A, Juenemann G, Peters B, et al. Determinants and consequences of atrial fibrosis in patients undergoing open heart surgery. Cardiovasc Res 2002;54(02):390-396

89 Wang GD, Shen LH, Wang L, Li HW, Zhang YC, Chen H. Relationship between integrated backscatter and atrial fibrosis in patients with and without atrial fibrillation who are undergoing coronary bypass surgery. Clin Cardiol 2009;32(09):E56-E61

90 Shingu Y, Kubota S, Wakasa S, Ooka T, Tachibana T, Matsui Y. Postoperative atrial fibrillation: mechanism, prevention, and future perspective. Surg Today 2012;42(09):819-824

91 January CT, Wann LS, Alpert JS, et al; ACC/AHA Task Force Members. 2014 AHA/ACC/HRS guideline for the management of patients with atrial fibrillation: a report of the American College of Cardiology/American Heart Association Task Force on practice guidelines and the Heart Rhythm Society. Circulation 2014;130(23):e199-e267

92 Camm AJ, Kirchhof P, Lip GY, et al; European Heart Rhythm Association European Association for Cardio-Thoracic Surgery. Guidelines for the management of atrial fibrillation: the Task Force for the Management of Atrial Fibrillation of the European Society of Cardiology (ESC). Eur Heart J 2010;31(19):2369-2429

93 Mitchell LBCCS Atrial Fibrillation Guidelines Committee. Canadian Cardiovascular Society atrial fibrillation guidelines 2010: prevention and treatment of atrial fibrillation following cardiac surgery. Can J Cardiol 2011;27(01):91-97

94 Siepe M, Pfeiffer T, Gieringer A, et al. Increased systemic perfusion pressure during cardiopulmonary bypass is associated with 
less early postoperative cognitive dysfunction and delirium. Eur J Cardiothorac Surg 2011;40(01):200-207

95 Todorov H, Janssen I, Honndorf S, et al. Clinical significance and risk factors for new onset and recurring atrial fibrillation following cardiac surgery - a retrospective data analysis. BMC Anesthesiol 2017;17(01):163-173

96 Cheng $\mathrm{H}$, Li Z, Young N, et al. The effect of dexmedetomidine on outcomes of cardiac surgery in elderly patients. J Cardiothorac Vasc Anesth 2016;30(06):1502-1508

97 Barber PA, Hach S, Tippett LJ, Ross L, Merry AF, Milsom P. Cerebral ischemic lesions on diffusion-weighted imaging are associated with neurocognitive decline after cardiac surgery. Stroke 2008; 39(05):1427-1433

98 Friday G, Sutter F, Curtin A, et al. Brain magnetic resonance imaging abnormalities following off-pump cardiac surgery. Heart Surg Forum 2005;8(02):E105-E109

99 Patel N, Horsfield MA, Banahan C, et al. Impact of perioperative infarcts after cardiac surgery. Stroke 2015;46(03):680-686

100 Samim M, Hendrikse J, van der Worp HB, et al. Silent ischemic brain lesions after transcatheter aortic valve replacement: lesion distribution and predictors. Clin Res Cardiol 2015;104(05): 430-438

101 Liu YH, Wang DX, Li LH, et al. The effects of cardiopulmonary bypass on the number of cerebral microemboli and the incidence of cognitive dysfunction after coronary artery bypass graft surgery. Anesth Analg 2009;109(04):1013-1022

102 Stroobant N, Van Nooten G, Van Belleghem Y, Vingerhoets G. Relation between neurocognitive impairment, embolic load, and cerebrovascular reactivity following on- and off-pump coronary artery bypass grafting. Chest 2005;127(06):1967-1976

103 Newman MF, Kirchner JL, Phillips-Bute B, et al; Neurological Outcome Research Group and the Cardiothoracic Anesthesiology Research Endeavors Investigators. Longitudinal assessment of neurocognitive function after coronary-artery bypass surgery. $\mathrm{N}$ Engl J Med 2001;344(06):395-402

104 Auffret V, Campelo-Parada F, Regueiro A, et al. Serial changes in cognitive function following transcatheter aortic valve replacement. J Am Coll Cardiol 2016;68(20):2129-2141

105 Spina R, Simon N, Markus R, Muller DW, Kathir K. Contrastinduced encephalopathy following cardiac catheterization. Catheter Cardiovasc Interv 2017;90(02):257-268

106 Dattani A, Au L, Tay KH, Davey P. Contrast-induced encephalopathy following coronary angiography with no radiological features: a case report and literature review. Cardiology 2018;139 (03):197-201
107 Manji RA, Grocott HP, Leake J, et al. Seizures following cardiac surgery: the impact of tranexamic acid and other risk factors. Can J Anaesth 2012;59(01):6-13

108 Myles PS, Smith JA, Forbes A, et al; ATACAS Investigators of the ANZCA Clinical Trials Network. Tranexamic acid in patients undergoing coronary-artery surgery. N Engl J Med 2017;376 (02):136-148

109 Hauville C, Ben-Dor I, Lindsay J, Pichard AD, Waksman R. Clinical and silent stroke following aortic valve surgery and transcatheter aortic valve implantation. Cardiovasc Revasc Med 2012;13 (02):133-140

110 O'Brien SM, Shahian DM, Filardo G, et al. The Society of Thoracic Surgeons 2008 cardiac surgery risk models: Part 2-Isolated valve surgery. Ann Thorac Surg 2009;88(1, Suppl):S23-S42

111 Hu Z, Wang Z, Ren Z, et al. Similar cerebral protective effectiveness of antegrade and retrograde cerebral perfusion combined with deep hypothermia circulatory arrest in aortic arch surgery: a meta-analysis and systematic review of 5060 patients. J Thorac Cardiovasc Surg 2014;148(02):544-560

112 Itagaki S, Chikwe J, Sun E, Chu D, Toyoda N, Egorova N. Impact of cerebral perfusion on outcomes of aortic surgery: STS adult cardiac database analysis. Ann Thorac Surg 2020;109(02):428-435

113 Brascia D, Garcia-Medina N, Kinnunen E-M, Tauriainen T, Airaksinen J, Biancari F. Impact of transfusion on stroke after cardiovascular interventions: Meta-analysis of comparative studies. J Crit Care 2017;38:157-163

114 Mao Z, Zhong X, Yin J, Zhao Z, Hu X, Hackett ML. Predictors associated with stroke after coronary artery bypass grafting: a systematic review. J Neurol Sci 2015;357(1-2):1-7

115 Werner N, Bauer T, Hochadel M, et al. Incidence and clinical impact of stroke complicating percutaneous coronary intervention: results of the Euro heart survey percutaneous coronary interventions registry. Circ Cardiovasc Interv 2013;6(04):362-369

116 Aggarwal A, Dai D, Rumsfeld JS, Klein LW, Roe MTAmerican College of Cardiology National Cardiovascular Data Registry. Incidence and predictors of stroke associated with percutaneous coronary intervention. Am J Cardiol 2009;104(03):349-353

117 Auffret V, Regueiro A, Del Trigo M, et al. Predictors of early cerebrovascular events in patients with aortic stenosis undergoing transcatheter aortic valve replacement. J Am Coll Cardiol 2016;68(07):673-684

118 O'Connor SA, Morice M-C, Gilard M, et al. Revisiting sex equality with transcatheter aortic valve replacement outcomes: a collaborative, patient-level meta-analysis of 11,310 patients. J Am Coll Cardiol 2015;66(03):221-228 